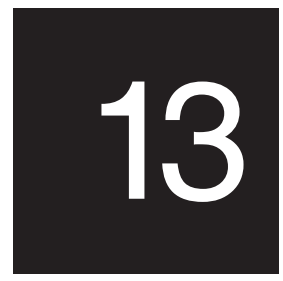

\title{
Culturally and ecologically sustainable tourism development through local community management
}

\section{Richard A. Engelhardt}

The question of how traditional cultures, in whole or in part, may be mobilised for economic and social development, without culture itself being destroyed in the process continues to be a major concern. After ten years of grappling with this issue during the World Decade for Culture and Development, and four successful years implementing projects to this end within the framework of the Vaka Moana program, our specific task now is to recommend to UNESCO not only how to continue the Vaka Moana program, but how to use experiences here in the Pacific to move the debate on culture and development to the next higher plane of policy, and to expand its application into action which penetrates deeply into our societies and sets an example throughout the world.

As the Director-General of UNESCO frequently reminds us, the twin pillars of UNESCO's mission-like that of all of the agencies of the United Nations system-are peace-building and development. Tourism is a factor in both. The spectacular rise in travel and tourism is one of the most significant changes in world trade in the second half of the twentieth century, generating more than US\$3.5 trillion in gross 
output a year and providing employment for well over 150 million people. Travel and tourism now account for 10 per cent of all world commerce. And nowhere in the world is tourism bigger business than in Asia and the Pacific. The World Travel and Tourism Council estimates that regional revenues which amounted to US $\$ 805$ billion in 1995 will grow at an annual rate of nearly 8 per cent over the next decade to reach US\$2 trillion by the year 2005 .

If UNESCO's ethical values are to be heard in the debate on sustainable development in the twenty-first century, tourism is one of the key industries where we must take an informed stance. To do so we must analyse the effects of tourism on society critically and evaluate its potential to contribute positively to the development of the cultural life of the world's communities. The Pacific island nations must find a place at the forefront of this debate, for the small and environmentally fragile countries in this region are some of the most susceptible in the world to both the negative-and positive-effects of tourism.

Tourism is a demand-driven industry inspired by the need of people to experience something different from their daily lives. Tourists travel to new places to see something cultural, historically significant or naturally beautiful, to experience new and alternative ways of perceiving the beauty and the richness of the world, through the eyes of other cultures. In short, they travel to seek, learn and experience the world's heritage.

On the supply side, the major stimulus for the development of tourism is economic. Tourism is often praised by economic planners as a labour-intensive, undifferentiated-service industry, requiring marginal start-up capital investment. Thus tourism ranks as a favourite development tool in less developed areas of the world with a large, unskilled labour pool. One also often hears that tourism is both 'environmentally-clean' and 'culturally-benign', fostering communication and understanding among peoples of different cultures, but what is the reality? Can unskilled, uneducated labour really be absorbed into the tourist industry? Who actually profits from the money tourism generates? And, as the numbers of tourists increase exponentially every year, what exactly is their impact on local cultures and the environment? These are questions to which we do not yet have clear-cut answers for the region and which need to be carefully researched. 
Tourism has brought a measure — sometimes a great measure-of wealth and economic development, at least to certain areas and to certain individual and business concerns. However, experience in Asia has shown that the rapid and unregulated growth of tourism in recent years has also been responsible for massive environmental destruction; for ruthless land expropriation; and for the exploitation of society's most vulnerable groups: ethnic minorities and young children who have the misfortune to become embroiled in the sex trade or forced to work as beggars on the fringes of affluent tourist resorts.

Not least among a nation's assets endangered by indiscriminate tourism are the historic monuments and ancient landscapes of the region's cultural heritage. These are fragile old structures which have a limited tolerance to the stress caused by visitors, their tour buses and their garbage. A heritage site has zero tolerance for thieves who wish to take home with them a piece of the monument as a souvenir.

Like rainforest, mangroves and coral reefs, the cultural heritage of Asia and the Pacific may be exotic and seductive attractions for both foreign and domestic tourists, but their carrying capacity does have its limits. Unless this limit is respected and visitors to these sites managed carefully, the sites will quickly deteriorate. Their demise will mean not only the loss of some of the most sacred, spectacular, historic and scientifically important places on earth, it will also mean the end of the tourist industry based on these cultural and natural treasures.

It is painfully obvious that the exponential tourism growth of the past four decades cannot continue indefinitely. There are limits to this growth imposed by the absolute carrying capacity of a tourism site. When this limit is reached, the site must either be closed to the public or will be degraded beyond repair. In either case, the site is lost to tourism. In the rush to provide expanded facilities for the rapid increase of mass-marketed tourism, the authenticity and integrity of indigenous traditional culture is all-too-frequently sacrificed. Ironically, it is precisely the authentic traditional culture and customs that tourists, both domestic and foreign, expect to experience when they visit a heritage site.

When there is an attempt by the tourism industry to expand the carrying capacity of the cultural or environmental resources of an area, these efforts typically take the form, not of conservation, but of promotional activities where complex cultural heritage is simplified, 
homogenised, packaged, and, in the end, trivialised for the quick and easy consumption of the tourist.

I will present two possibly successful models of culturally sustainable tourism development. However, mine is nevertheless a cautionary tale. Tourism presents a viable option for Pacific island states to participate in the global economy, but only if this option is carefully considered and, if taken up, even more carefully regulated.

\section{Tourism and cultural preservation}

Discussions on the growth of tourism are always lively, and because they draw points of view from different sectors-archaeological, commercial, anthropological, architectural, even political—these debates have not always resulted in clear or harmonious points of convergence. The battle line is drawn between those who wish for the economic opportunity and development of the area at whatever cost, and those who would preserve or conserve culture and environments in a pristine state.

Tourism and preservation may appear to be strange bedfellows, but with proper management a synergy can be developed. Sustainable tourism can bring improved income and living standards for local people. Tourism can revitalise local culture, especially traditional crafts and customs. It can stimulate the rural economy by creating demand for agricultural produce and, through infrastructure development projects, it can inject capital into rural areas.

Informed and expert tourism also has the potential to play a vital role in the preservation of the cultural heritage of a nation.

Maintenance and preservation of cultural heritage can lead to increased awareness of, and pride in, history and civilisation. Tourism can also help preserve and develop national culture by providing a wider patronage for handicrafts and traditional performing arts. UNESCO's concern therefore is to promote the development of cultural tourism, not as an end unto itself, but as a tool for the preservation and enhancement of a society's culture, its physical and intangible heritage, and its environment.

This reassessment of the purpose of tourism development may seem to be a radical approach, but it gives an invigorating sense of purpose and direction to sustainable tourism development and to the tourism industry as a whole. It makes good economic sense. If the cultural and environmental resources on which tourism is based are 
not conserved, the industry cannot be sustained. It is also good public relations strategy for the tourism industry to be seen as pro-culture and pro-environment, which, indeed, it surely must be if it is to survive.

The specific role of UNESCO in this realignment of the tourism industry is to encourage linkages between community development and heritage preservation, through local effort, public-private partnerships and by strengthening, through training, local-level endogenous capacity in heritage preservation and management. In this way we attempt to promote the essential role of culture in development, recognising that cultural traditions and practices provide the most stable basis for sustainable social and economic development.

To make tourism a viable tool for cultural and environmental conservation, several issues will have to be addressed and improved

- information for the potential tourist (promotion)

- quality (authenticity) of tourism products and sites (interpretation)

- conservation and management of sites with respect for a site's carrying capacity. This will require that the tourism industry cooperate with and work under the guidance of professional conservators

- financing, so that the increased needs of the sites in terms of maintenance and presentation which tourism demands are able to be met from the profit revenues of the tourism industry, not from dwindling public funds

- endogenous planning, indigenous management, and profitsharing by the affected local community.

\section{Two case studies, from Vietnam and Laos}

\section{Hue, Vietnam}

I will start with Hue because it is a more straightforward type of site and because I want to dispel any notion which I may have mistakenly conveyed that local community empowerment is the panacea to all tourism development issues. All development issues are management issues embedded in a matrix of power at the family, village, tribal, national, regional and global levels. Tourism is no different and the failure of sustainability from which so many tourism development schemes suffer is caused precisely by the failure to reconcile the interests of all stakeholders. 
Hue is the former royal capital of Vietnam. Inscribed on UNESCO's World Heritage List in 1993, it was the subject of a priority international safeguarding campaign by UNESCO from 1994-95. The purpose of this campaign was to restore the site and the traditional culture associated with it, not only by conserving the physical remains but also through the revitalisation of Vietnam's intangible cultural heritage which had been trivialised by colonisation, discredited by political ideology and decimated by war.

The challenge in Hue has been to take a rather decrepit, although emotionally significant, cultural heritage site and to bring it back to life by re-discovering the crafts, sciences, tools, materials, but also the landscapes, music, food, activities, art and poetry which were associated with it. This also is a challenge familiar in the Pacific with its rich, but sometimes eroded, heritage of intangible culture. The challenge for tourism development at Hue and at many sites in the Asia Pacific region is the same: how to keep what is sacred, sacred; how to retain or revitalise the richness, complexity and creativity of the traditional performing arts; how to maintain cultural authenticity and communicate an appreciation of this to the visitor-both foreign and domestic - privileged enough to experience it.

At the present time, tourism in Hue is still small-scale and manageable, but it is expanding quickly. As part of UNESCO's campaign to safeguard the site, and with the help of students from the Hue University, the local business association undertook econometric studies to address the potential contribution of cultural tourism to the rehabilitation of the socioeconomic life of Hue.

Based on the results of this study, a year-long series of training workshops was conducted for both public and private sector players interested in developing tourism at Hue. These workshops targeted a wide spectrum of stakeholders: land developers and hotel entrepreneurs; local historians and students looking for employment in the tourism industry; cyclo drivers and souvenir vendors; even handicapped street people who formerly begged for alms outside the monuments and temples.

The workshops resulted in a detailed tourism development management plan that was compiled for the guidance of everyone. The specific provisions of this plan were re-debated at length by the local and regional People's Committees then adopted and sent to the Prime Minister for promulgation as policy. 
In outline format, the Hue Plan for Sustainable Tourism Development, makes the following statements with regard to financing, zoning and integration of living culture into a heritage site tourism development plan.

Finance. Although heritage conservation is not incompatible with sustainable tourism development, there must be a well thought-out plan that is used by all actors as the basis for this development, if the concerns of heritage preservation are to be given due consideration. Following a well thought-out master plan can, in fact, lead to the reinvigoration of traditional cultures by creating new audiences (that is, consumers) for traditional culture and offering the possibilities of financing this cultural revival with tourist revenues. In outline,

- an overall development master plan incorporating both preservation and development concerns is required for the guidance of all

- sustainable cultural tourism implies increased investment to maintain and/or invigorate the cultural resources on which tourism is based

- financing for the necessary increases to investment in culture can and should be found within the profit margins of the tourism industry

- innovative public-private partnerships can be established to link conservation efforts to sustainable tourism development.

Zoning. Although an increase in visitors to a site can bring economic benefits, the increase in the number of people is in itself problematic because of the additional stress it places on the already fragile monuments. Therefore it is important to determine and respect the limits of the carrying capacity of each monument, site or facility. Consequently,

- there is an upper limit to the number of visitors a historical/ cultural site can receive at any one time without the site suffering permanent degradation or damage

- strict zoning and land-use regulations must be put in place and scrupulously enforced in order to preserve the traditional environmental context of the historical monuments and sites

- integrated, inter-agency planning is essential both at the national and the local level if the twin goals of heritage conservation and sustainable tourism development are to be successfully achieved. 
Integrating living and historical culture. It is both desirable and possible to expand both the carrying capacity of a site and the touristic interest of a site by integrating intangible culture with the physical heritage. A lively local culture of dance, theatre, poetry, painting and even food, all encourage a visitor to stay longer in the area and give the visitor a greater depth of understanding about the traditional local culture. Research documentation and training are necessary in order to ensure that the authenticity of these intangible cultural traditions is scrupulously preserved. In brief

- cultural tourists are seeking a high-quality, informed and authentic cultural experience

- in addition to the historical monuments, traditional vernacular villages, rural temples and the natural environment, are also of particular interest to the visitor and form part of the unique 'cultural landscape' of a site

- investment in training and human resource development in the performing and other traditional arts is, therefore, good tourist economics

- personnel, drawn from the local community and thoroughly trained in the presentation of a cultural site and its maintenance, are crucial to the successful development of cultural tourism as a sustainable business.

The Vietnamese tourism development plan for Hue shows that conservation and preservation of cultural heritage through cultural tourism depends on the combined efforts of the different stakeholders. A strong government policy on cultural tourism and heritage preservation is important, but this must be accompanied by a commitment at the local level to ensure that policy is carried out. Cooperation among institutions and agencies involved in tourism is also needed to bring finance and state-of-the-art expertise to this effort. The contribution of the mass media and the education system are also vital in increasing the awareness of the entire local population concerning the importance of preserving historical building and archaeological sites.

\section{Luang Namtha, Lao PDR}

Although Laos is a landlocked country, it presents many development analogies to Pacific island states in terms of its isolation, small population, low GDP, a regional approach to development based on historical ties, trade and migration routes, and intimate links between 
its natural environment and culture. Laos, like some of the Pacific states, is, according to the United Nations, also one of the world's 'least-developed economies'. A crucial aspect for policy formulation in Lao PDR is the way in which culture and the natural environment are interlinked. Forty per cent of the land is under forest and these forests are home to 68 different ethnic groups.

Recognising the wealth of this heritage, the Lao government has made a commitment to the preservation of its cultural heritage and natural environment. However, a single-minded, country-wide commitment to the preservation of tropical forests and rivers in their pristine state is not a viable political option for Laos. The imperatives of poverty alleviation and economic development dictate that the natural environment be put to economically productive use. The task for policymakers is to accomplish this on a sustainable basis, with a minimum of environmental degradation and in such a way as control of the environment remains in Lao hands.

The biggest asset of developing countries is often their beautiful natural landscape and unique, living traditional culture, therefore governments frequently seek to market their countries through tourism as an immediate way to earn foreign exchange. Laos has also chosen this option.

With the opening of the Lao PDR to international and interregional tourism, there are increasing internal and external pressures on the national and local tourism authorities to approve and invest in a wide variety of tourism products and to improve the infrastructure to support the growing tourism industry. However, a too rapid expansion of the cultural and ecotourism industry without adequate regard for the carrying capacity of the environment, or without a mechanism for providing the funds and technical expertise for the required increase in conservation, will prove devastating both to the ecotourism industry and to the cultural heritage of Laos.

Urgent assistance is required to ensure the creation of a sound tourism investment policy, which guarantees that a major percentage of the economic benefits earned by tourism stay within the country and are applied in ways that directly benefit the population of that country. Without this assistance in economic policy formulation, grassroots community empowerment will have little long-term effect.

There is an urgent need to enhance the capacity of Lao tourism planners and authorities to handle this situation in a proactive way, and to create mechanisms for the direct participation of communities 
affected by increased tourism in order to bring economic benefits, safeguard the environment, and maintain cultural and spiritual values intact.

The challenge presented to UNESCO by the National Tourism Authority of Laos was to assist the national authorities to meet these needs by developing sustainable 'ecotourism' in the 24 'national biodiversity conservation areas' which together comprise fully onequarter of the total land area of country. This daunting task was complicated by the fact that all of the 24 conservation areas are home to significant numbers of minority tribal peoples, some of whom have been identified by UNESCO as having among the most endangered cultures of the world.

'Ecotourism' is a term loosely used by the tourism industry to connote organising tourist activities around visits to natural scenic locations and visits to villages of the local inhabitants. Usually this appellation is merely politically-correct advertising copy, disguising the all-too-familiar exploitation of people and environments by massbased tourism.

However, 'ecotourism' also has the potential to be a significant development activity, in which case its proper implementation is considerably more complicated than taking tourists for a hike in a forest or diving on a coral reef. The Ecotourism Society's 1992 definition of ecotourism is 'purposeful travel to natural areas to understand the cultural and natural history of the environment, taking care not to alter the integrity of the ecosystem, while producing economic opportunities that make the conservation of natural resources financially beneficial to local citizens.' The 1995 Australian National Ecotourism Strategy defines ecotourism as 'tourism that involves education and interpretation of the natural and cultural environment and is managed to be ecologically sustainable.'

UNESCO assistance to Laos-co-financed by the government of New Zealand and by the first-ever grant to UNESCO by the International Finance Corporation-consists in fostering the articulation of an endogenous tourism management plan. A plan based on traditionally evolved practices of land use and stewardship, and consideration of criteria and the commercial viability of private investment. The goal is to ensure that local cultural communities can continue to manage their environments sustainably and in accordance with established traditional practices while simultaneously developing their economic potential through ecotourism. 
The participants of this project and its beneficiaries are

- Lao authorities at the provincial and district levels whose position at the regional is equivalent to national level forestry, cultural and tourism offices and who have been assigned the task of developing tourism in their regions

- the local communities who live in and around these protected areas targeted for tourism development, especially ethnic and cultural minorities, youth, women and local culture specialists

- Lao and foreign investors who wish to invest in commercially viable ecotourism projects in an environmentally and culturally sustainable way.

Project activities emphasise the sustained economic development of natural and cultural resources by planning and promoting environmentally sound and culturally appropriate ecotourism, which is community based and ensures that any benefits will be shared with the affected communities through the generation of employment and other economic opportunities. The involvement of local communities in decision-making and the distribution of economic benefits is essential to achieve long-term sustainable development in the area.

To this end, endogenous models of cultural and ecotourism development, based on traditional community land management practices - to the extent that they continue to be sustainable - and technical expertise from the natural and cultural conservation sciences have been developed in northern Lao PDR. The models are now being tested and evaluated in one particularly vulnerable and protected area bordering China and Myanmar: Luang Namtha.

The criterion used to evaluate the models is their success in attaining non-subsidised, commercial viability, providing local employment opportunities and contributing to raising the standard of living of the people of the area to comparable national levels, contributing to their long-term welfare and allowing them to maintain the integrity of their social and cultural traditions.

The models developed in Luang Namtha hopefully will be applicable to cultural and ecotourism development in the other protected areas of the Lao PDR, with modifications to fit local environmental, cultural and developmental conditions. These models will serve to guide both public and private sector investment in this industry, leading to job creation in rural areas, enabling local 
communities to participate in the management and conservation of their natural and cultural resources for the sustainable development of tourism and other economic sectors.

\section{Conservation problems at world heritage sites}

The results of a recent survey of conservation problems at World Heritage sites attribute the major problems to unmanaged tourism development and the resultant degradation of the environment of the site.

The conclusion is that sustainable culture/tourism equates to the safeguarding of the cultural and natural environment on which this tourism is based. Unfortunately, standard models of tourism development in many areas of the region remain volume-oriented, driven by macroeconomic considerations, and by a private sector which indiscriminately pursues mass tourism with little regard for culture, ecology and social values.

Carefully planned, managed and controlled tourism that services and enhances heritage preservation is an attractive alternative and can be economically profitable if the following objectives are maintained

- use of the country's cultural and natural resources to stimulate the development of a tourism industry which will play a significant role in national economic growth

- development of tourism as a tool in the conservation of the country's cultural and natural heritage and the preservation of the complex linkages between culture and environment

- enable tourism related to the country's cultural and natural heritage to prosper without damaging that heritage or engendering social problems

- development of tourism in a manner that keeps control and operation in the hands of local peoples and allows local peoples to reap the fruits of the business.

Community participation in the planning and implementation of a tourist development plan is essential. This will serve to mitigate the negative social aspects which mass tourism brings and to provide guidelines for appropriate tourist behaviour in historically important but culturally fragile sites. Community involvement in the planning of social activities focused on its cultural heritage will also enrich the cultural calendar with fairs, festivals and theatrical performances for the enjoyment and education of not only tourists, but local residents as 
well. When local people are active participants in all of these activities they will develop a personal stake in the development of long-term sustainable tourism through the conservation and maintenance of the authentic cultural heritage of their community.

Cultural heritage is not a static relic from the past. It is the very basis of development. Cultural values determine the priorities a society sets for its future economic and social development. Plumbing the wisdom of human cultures we can find the inspiration and the courage to manage the complexity which challenges the region, to realise the aspiration to diversity and to create new forms of solidarity for future peace and prosperity.

\section{Conclusion}

I began with a reference to the need to develop specific recommendations for the continuation and development of the Vaka Moana program. I hope that my remarks have suggested to you some ideas in this regard both with regard to sustainable cultural tourism development and with regard to the promotion of effective local community management of cultural resources. I cannot presume to advise you on the future of Vaka Moana, but I can suggest three general areas of action that might be appropriate in regard to sustainable tourism development.

- There is a need to elaborate regional, national and local guidelines for undertaking cultural impact assessments; such assessments should be required by law prior to the approval of each (tourism) development activity.

- There is a need to undertake national inventories, including surveys and maps, of all immovable physical cultural heritage and sites - and to determine their visitor carrying capacity-with a view to their long-term protection within the framework of the 1972 UNESCO World Heritage Convention, and other appropriate international, national, local and customary conservation instruments.

- There is a need to develop, where they do not already exist, instructional modules for teaching regional, national and, especially, local heritage in the formal school system. With special reference to tourism development, there is a need for teaching school-leavers in non-formal situations with the particular aim of training and licensing local heritage expert guides and resource persons. 